\title{
Co-operative Investment Policy as a Tool to Accelerate the Entrepreneurship and Improve the Poverty Condition in Bangladesh
}

\author{
Raju Mohammad Kamrul Alam¹, Md. Nazmul Hossain ${ }^{2}$ and Al Humssi Ahmad ${ }^{3}$
}

\begin{abstract}
Bangladesh is one of the poorest countries in the world with low GDP/capita and minimum purchasing power. A third of the total population (24.3\%) lives below the national poverty line $(\$ 2 /$ day) while a half of them do live in extreme poverty level $(\$ 1.25)$. It's now a national issue as high rate of poverty is the cause of permanent economic downturn and socio-economic depression in Bangladesh. Many policies have been applied by government and NGOs since its independent in 1971 to alleviate the poverty but no policy has brought a remarkable outcome. The main purpose of the study is to examine the causes for high rate of poverty in Bangladesh and insufficiency of the government agencies that are working to alleviate the poverty and propose innovative approaches to growth of entrepreneurship to bring sustainable economic growth and improve the poverty condition. The study is based on structural and semi-structural questionnaires and face to face interview. A total of 60 structural and same numbers of semi-structural questionnaires were given to 100 recipients of various age, sex, education, profession and economic levels regarding the factors to get feedback. In this research, a cooperative investment policy and a government action plan have been drawn up based on coordination between the various agencies, which allow the impoverished section of the population to save and invest collectively in order to involve them in entrepreneurship to lift themselves out of the poverty cycle and bring sustainable development. The aim of the research involving the impoverished population to entrepreneurship through co-operative investment policy and promoted government mechanisms to improve the poverty condition in Bangladesh. Search tasks: *To examine the major reasons for the high rate of poverty in Bangladesh. *To explore the impacts of entrepreneurship to accelerate the economic growth and improve the poverty condition in Bangladesh. *To discover the most effective ways to involve the impoverished population to entrepreneurship. ${ }^{*}$ To develop a co-operative investment policy and an integrated government strategy covering all financial, administrative, supervisory and regulatory aspects that will regulate the state's action to accelerate the entrepreneurship and achieve economic growth. Subject of the research cooperative investment policy and improved government mechanism for poverty reduction in Bangladesh through entrepreneurship growth. Object of the research the rate of poverty, entrepreneurship.
\end{abstract}

Keywords: Impoverished Population, Co-operative Investment Policy, Entrepreneurship, Government Performance, Sustainable Development.

\section{Introduction}

Small and Medium Enterprises (SMEs) play a significant role in employment creation and income generation in many developing countries. The role is particularly crucial in the national efforts to eradicate poverty.

Bangladesh is one of the poorest countries in the world. A third of the total population (164.8 million) lives below the national poverty line (\$2/day) (World Bank 2017). A million of people are homeless and further a million of people are hidden homeless. A

${ }^{1}$ Ph.D., Senior Lecturer, Faculty of Economics, RUDN University, Moscow, Russia

${ }^{2}$ Ph.D. Student, Faculty of Economics, RUDN University, Moscow, Russia

${ }^{3}$ Ph.D., Faculty of Economics, RUDN University, Moscow, Russia 
million of people die cause of starving and malnutrition every year.

There are 3 fundamental reasons which are accountable for permanent economic downturn and tremendous poverty in Bangladesh, are: firstly, the poor people don't have permanent regular jobs to earn enough money to support their families due to their lack of working skills and experience. Secondly, they don't have sufficient investment capital to introduce their own businesses or other income generation activities to change their financial status. And thirdly, they don't have proper entrepreneurial and managerial knowledge and experience to introduce and operate their own businesses perfectively profitably. These factors confine them into poverty cycle from generation to generation and impose tremendous pressure on national economic, infrastructural and economic growth plan and potentiality.

To counter the high rate of poverty, the country needs a sustainable level of growth of SMEs to accelerate the economic growth and generate employments. Having predominance of agro-based economic activities, low level of technological presence and an abundance of low and semi-skilled labor forces, SMEs have been suitable for economic growth and employment generation. Moreover, due to the structure and special characteristics of the SMEs in Bangladesh, which creates self-employment and employment for low and semi-skilled workers, the growth of SMEs is considered to be the most remarkable contributor to the national economic growth and eradication of poverty.

But the way for growth of SMEs is not smooth enough in Bangladesh. They are frequently confronted with structural, financial, infrastructural, and social constraints.

To prevent the impediments and to smooth the growth of SMEs, the government of Bangladesh has taken various initiatives including, policy advocacy and intervention for growth of SMEs, facilitating financial supports for SMEs investors, providing skill development \& capacity building training, facilitating adaptation with appropriate technologies and access to ICT, and providing business support services through the SME Foundation created under the ministry of industry in 2007. Moreover, to outplay the financial access barrier, many NGOs and MFIs (Micro Financial Institutes) since 1974, have been playing very significant role to accelerate the growth of SMEs by providing collateral free loan to the impoverished investors.

But despite the initiatives, growth of desired scale of SMEs is still lagging behind. To get the real growth, actual needs of SMEs are needed to be addressed and effective policies are needed to be adopted including, favorable government policy, easy accessible financial services, good infrastructure, development of human capital, good micro economic policy, entrepreneurial knowledge \& training to entrepreneurs, favorable regulatory framework and SMEs development programs and use of changing pattern of technology. Both government and the private sectors have to play a significant role through policy making and institutional supports for this quest.

Cooperative Investment Policy whereby little deposit capitals of many impoverished individuals are aggregated gradually in co-operative manner and invested in labors productive and profitable sectors as their (impoverished investor's) own financial institutes (SMEs \& MIAs), in which they are employed with their shareholder status, could be a viable alternative; is the main objective of the paper. The study is to see the impacts of Micro-saving Based Cooperative Investment Policy on socio-economic spheres in Bangladesh. 


\section{Theoretical Background}

The literature on role of SMEs in economic growth and improve the poverty condition is reviewed and major obstacles for growth of SMEs has been revealed. It also includes the conceptual and theoretical framework of assessment of SMEs in Bangladesh and beyond. The researcher includes the result of past impact assessment studies of SMEs in economic growth and poverty alleviation and major obstacles for growth of SMEs in Bangladesh and other countries in the world.

There is consensus among policy makers, economists and business experts that SMEs are important driver for economic growth and poverty alleviation. A healthy SME sector contributes prominently to economy by creating employment opportunities, generating higher production volumes, increasing exports and enhancing innovation and entrepreneurship skills. The dynamic role of SMEs in developing countries insures them as engines by which the growth objectives of developing countries can be achieved (Chris Hall 2010).

At the community level and by extension the whole economy, the contribution of SMEs to GDP growth, employment generation and other economic development parameters in both developed and developing countries in succinctly summarized by James Richardson (2004) as follows: greater utilization of raw materials, encourage of rural development, mobilization of local savings, provision of regional balance by spreading investments more evenly, provision of avenue for self-employment and provision of opportunities training managers and semi-skilled workers. Thus, the role of SMEs in developing any economy cannot be over emphasized. The impacts of SMEs in economic growth and poverty alleviation are mainly based on three fundamental factors (World Bank, 1994). Firstly, SME advocates argue that SMEs enhance competition and entrepreneurship and hence have external benefits on economy-wide efficiency, innovation and aggregate productive growth. 2ndly, proponent of SME supporter frequently claim that SMEs are usually more productive than large scale enterprises. And finally, it's argue that SMEs' expansion boots employment more than large firm growth as SMEs are more labor intensive. From this point of view, subsidizing SMEs may represent a poverty alleviation tool.

The assistance of SMEs to any economy is indispensable, as SMEs are known to contribute to development of several economics in term of output of goods and services and creation of employments at relatively low investment cost Pang, P. (2008). SMEs also improve forward and backward linkage between economically, socially and geographically diverse sectors of many economies (SMEDAN, 2005). Thus, the development of SMEs is an essential component in the growth strategy of many economies.

An emerging economy requires a sound industrial base which can stimulate growth (Haque, 2006) this is achieved when SME concentration is high as they provide employment and output in the initial phase of transformation from a low-income economy to middle-income economy and assist in a smooth and fast track transition itself.

SMEs play an important role in the transition of agriculture-led economics to industrial one. They also assist to absorb productive resources (local technology and raw materials) that would have otherwise been neglected by large industries at all level of economy and 
add to the formation of flexible economic systems in which small and large firms are interlinked (SMEDAN 2010).

SMEs have good impacts in economic growth and poverty alleviation in Bangladesh too. According to a study conducted by Chowdhury (2009), imposed on 1500 SMEs operated in rural and urban areas in Bangladesh between 2007 and 2008, SMEs involving relatively small technology, low investment and having capable of generating large employment opportunities, has a vital role in socio-economic spheres in Bangladesh. Moreover, it's a vital source for innovation and growth.

\section{Methodology}

The research depends on two phases. The first stage is the diagnosis of the problem and the second stage is finding solutions of the problem. To support the methodology, the questionnaire method was adopted to support the results. The research focused on the Bangladeshi Community aged 18 and above, including both male and female recipients. The target samples for this study consisted of 100 recipients of Bangladeshi Community around the country including cities and rural areas for this study, were chosen randomly.

\section{Findings and Discussion}

In Bangladesh SMEs can play a significant role for sustainable economic growth and improve the poverty condition. But the ways for growth of SMEs are not smooth enough. They are frequently confronted with financial, legal, infrastructural and social constraints. The most remarkable hurdles faced by the SMEs in Bangladesh are the following:

\section{Access to Finance}

Inadequate access to finance is one of the most significant constraints for growth and development of SMEs in Bangladesh. Inadequate access to finance includes lack of short, medium and long term capital, non-accessibility to financial resources and credit facilities. Financial access inadequacy to small farmers and weaker sections of the society has been recognized as a serious threat to economic progress in Bangladesh. Moreover, prolonged and persistent deprivation of banking services to a large segment of the population leads to a decline in investment. In Bangladesh $85 \%$ of small business is identified access to finance as a major impediment. When testing a random sample of a group of people from the total population that lives below the poverty line within different ages concerning the factor, the result is shown in the table 1:

Table 1: Shows that it agrees not to be able to invest heavily due to the ability to access adequate funding

\begin{tabular}{|c|c|c|}
\hline Age group & Number of people in the group & Lack of adequate funding $\%$ \\
\hline $18-29$ & 38 & $99.2 \%$ \\
\hline $30-49$ & 50 & $99.4 \%$ \\
\hline $50-60$ & 12 & $100 \%$ \\
\hline
\end{tabular}

Source: collected by the researcher based on the results of the questionnaire 


\section{Political instability}

Political instability is confrontational for the growth and development of SMEs in Bangladesh. Personal and political enmity between rivals, frequent hortals (Strikes) and lack of respect for elementary principles of domestic governance have become the principle characteristics of the country's political system. A series of prolong hortal affects the political stability which hinders the growth of SMEs and socio-economic development. Every fiscal year, Bangladesh is losing 3-4\% worth of GDP to political depression mainly to hortal. These syndromes have given birth to a culture of corruption, bribery, hooliganism as brinkmanship discourage the development of entrepreneurial talents and initiatives in the country through the non-adherence of any rule of law.

\section{Cultural Restriction}

Women make almost half of the total population in Bangladesh [49.586 (f): $50.414(\mathrm{~m})$ ], but their involvement in financial activities is very limited. As of 2015, a merely 18.3 million (31.6\%) female workforces are available in Bangladesh labor market against 43.1 million $(79.7 \%)$ of the male workforces. Moreover, in term of entrepreneurial activities, they are also lagging behind of their male counterpart. As of 2017 , only $7.2 \%$ of 3.7 million SMEs were owned by female entrepreneurs. Their contribution to national GDP is also very small, only $6.85 \%$ to the total GDP.

For sustainable economic growth, women's involvement in economic activities is indispensable. The low involvement of women in financial activities, $84 \%$ of the recipients blame the cultural setting. Questionnaires related to women's investment obstacles faced by women entrepreneurs are in the following tables 2 :

Table 2: Obstacles female investor usually faces in case of investment

\begin{tabular}{|l|c|c|}
\hline & F & M \\
\hline People & 25 & 75 \\
\hline Religious barriers & $4 \%$ & $24 \%$ \\
\hline Traditional barriers & $84 \%$ & $72 \%$ \\
\hline Political obstacles & $4 \%$ & $4 \%$ \\
\hline N/G & $8 \%$ & - \\
\hline
\end{tabular}

Source: collected by the researcher based on the results of the questionnaire

\section{Quality of Education}

In Bangladesh, education is below the standard quantitatively and qualitatively both in school and higher education levels to creates human capital and enhances peoples' productivity, creativity and promotes entrepreneurship and technological advances. 5\% of the total school aged children don't go to school, another $5 \%$ dropout before finishing the primary school and around 70 percent of children are unable to read or write properly, or perform basic mathematical calculations even after five years at primary school (BRAC 2013). Universities in Bangladesh are also below the standard and being failed to create human capital, entrepreneurs and inventors. 5 out of 10 graduates in Bangladesh are unemployed (The Daily Star, March 8, 2015). Lack of qualified teachers and poor facilities in terms of the number of institutes (Schools), teachers, classrooms, libraries and playgrounds are responsible for poor quality education in 
Bangladesh (at school levels). In the university level, theoretical based non-technical education is mainly accountable to fail to create sufficient human capital and entrepreneurs.

\section{Lack of entrepreneurial Knowledge and Experience of Entrepreneurs}

Lack of entrepreneurial knowledge is one of the most remarkable bottlenecks which impede the growth of SMEs and tributes for high rate of SMEs failure in Bangladesh. Every year 1/3 of new SMEs is introduced in Bangladesh but 2/3 of them can't survive longer than 1 year. This is primarily due to lack of entrepreneurial, managerial, marketing and bookkeeping knowledge and experience of SMEs' investors. Most of the SMEs in Bangladesh are introduced without any plan, outline or framework. 89\% of the owners of small businesses practically do the business plans by themselves without seeking consultation from professionals or experts. This has resulted to incompetence, inefficiency, wastage and under-utilization of resources available to the organization.

\section{Legal, Regulatory and Administrative Constraints}

In Bangladesh there is no supportive act (law) to smooth the growth of SMEs. Moreover, investment functions are bureaucratic and complex with a lot of paper works and red tape barriers. To introduce small business in Bangladesh, according to the Companies Act (Act XXVIII) of 1994, it is obligatory for the investors to procure trade license from local government bodies by paying statutory fees. But the SME investors are to confront with harassment, unexpected delay and side payment due to the administrative bureaucracy and corruption. Thus, investment cost of SMEs goes unexpected high and many investment projects are dropped out every year. Questionnaires related to the obstacles small enterprises faced are in the table below:

Table 3: Obstacles Small Enterprises faced

\begin{tabular}{|l|c|c|c|c|c|}
\hline Questions & \multicolumn{5}{|c|}{ Answers } \\
\hline a. Access complexity to formal financial services? Yes / No & $94 \%$ & $6 \%$ & - & - & - \\
\hline b. Lack of adequate funding? Yes / No & $98 \%$ & $2 \%$ & - & - & - \\
\hline c. Red tap? Yes / No & $92 \%$ & $8 \%$ & - & - & - \\
\hline d. Corruption? Yes / No & $95 \%$ & $5 \%$ & - & - & - \\
\hline e. Political instability? Yes / No & $89 \%$ & $11 \%$ & - & - & - \\
\hline f. Infrastructure deficiency? Yes / No & $78 \%$ & $22 \%$ & - & - & - \\
\hline g. Unprotected intellectual property? Yes / No & $12 \%$ & $88 \%$ & - & - & - \\
\hline h. Sharp competition or monopoly? Yes / No & $13 \%$ & $87 \%$ & - & - & - \\
\hline i. The inability to complain to the competent authority? Yes / No & $14 \%$ & $86 \%$ & - & - & - \\
\hline j. Is the inability to compete with major companies? Yes / No & $10 \%$ & $90 \%$ & - & - & - \\
\hline What are the main obstacles encountered or faced? a/b/c/d/f & $74 \%$ & $3 \%$ & $7 \%$ & $6 \%$ & $10 \%$ \\
\hline
\end{tabular}

Source: collected by the researcher based on the results of the questionnaire

To growth of entrepreneurship and improve the poverty condition in Bangladesh, the author proposes a mechanism for state regulation, including the following blocks:

I. Subject of growth of entrepreneurship and improve the poverty condition:

- The first level -Government, the Ministry of planning, the Ministry of Finance, the Ministry of Industry, the Ministry of Education, the Ministry of Economy and Foreign Trade, the Bangladesh Investment Development Authority and other bodies; 


\section{- The second level - National Bureau of SMEs}

II. Object of growth of SMEs and improve the poverty condition: Impoverished sector of the population, Rural and disadvantage areas, Educational Institutes (Schools, vocational training institutes, University and research institutes), local government, NGOs, Banks, MFIs, the federation of Bangladesh Chambers of Commerce and Industry (FBCCI);

III. Tools and measures aimed at the growth of SMEs and improve the poverty condition in Bangladesh:

The measures to improve the poverty condition include financial, legal, educational and organizational priorities. To organize and improve the efficiency of the activities of the subjects of growth of entrepreneur and improving the poverty condition in Bangladesh, it is recommended to use the experience of Malaysia in this field (law on the coordination of ease of doing business and education to create human capital)

In order to prevent governmental problems to accelerate the entrepreneurship and combat poverty, it is necessary to establish a specialized center with broad powers in order to raise the efficiency and coordinated performance. In this research we propose to create a "National Bureau of SMEs" as the following (NBoSMEs)

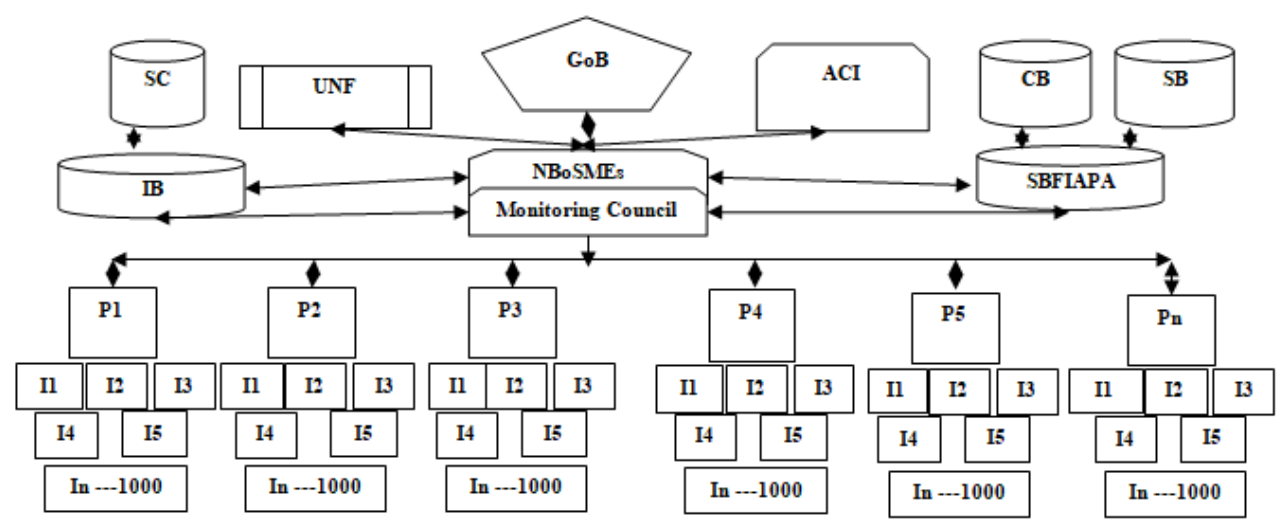

GoB: Government of Bangladesh; SC: National Statistical Centre; UNF: Universities; IB Information Bank; SBFIAPA: Savings Bank for Finance and Combating Poverty; NBoSMEs: National Bureau of SMEs; Monitoring Council Office Coordinator $\mathrm{P} 1, \mathrm{P} 2, \mathrm{P} 3, \mathrm{P} 4, \mathrm{P} 5$, Pn Small and medium-size enterprises

\section{Role of Government}

- To ensure compatibility between the pre-planned plans and the plans issued by the Investment and Poverty Alleviation Center

- Securing communication with all government agencies and ministries

- Imposing laws to run the business center

- Authorization of the Center

- Monitoring the work of the center

- Verify the achievement of the goals set by the Center

- Provide advice to the Center 
- Settle the dispute the differences resulting from the conflict between the Center and other governmental and non-governmental entities

- Appointment of the head of the center and the executive members of the center

- Provide the conditions for investment by providing the infrastructure

\section{The objective of the Center}

- To develop investment plans to combat poverty, raise the living standards and achieve investments

- Provide funding

- Urge ministries to make adjustments to align with plans

- Feasibility study of projects

- Monitoring the process of savings, loans and investment

- Coordination between the work of companies

- Coordination with the Central Investment Authority

- Providing plans for projects in accordance with scientific research in universities

- Provide the protagonist crisis

\section{Monitoring Council}

Monitoring Council or Office Coordinator One window is the only medium between the center and SME management. Its purpose is to prevent any direct contact between the different bodies, whether they are executive, monitoring or administrative

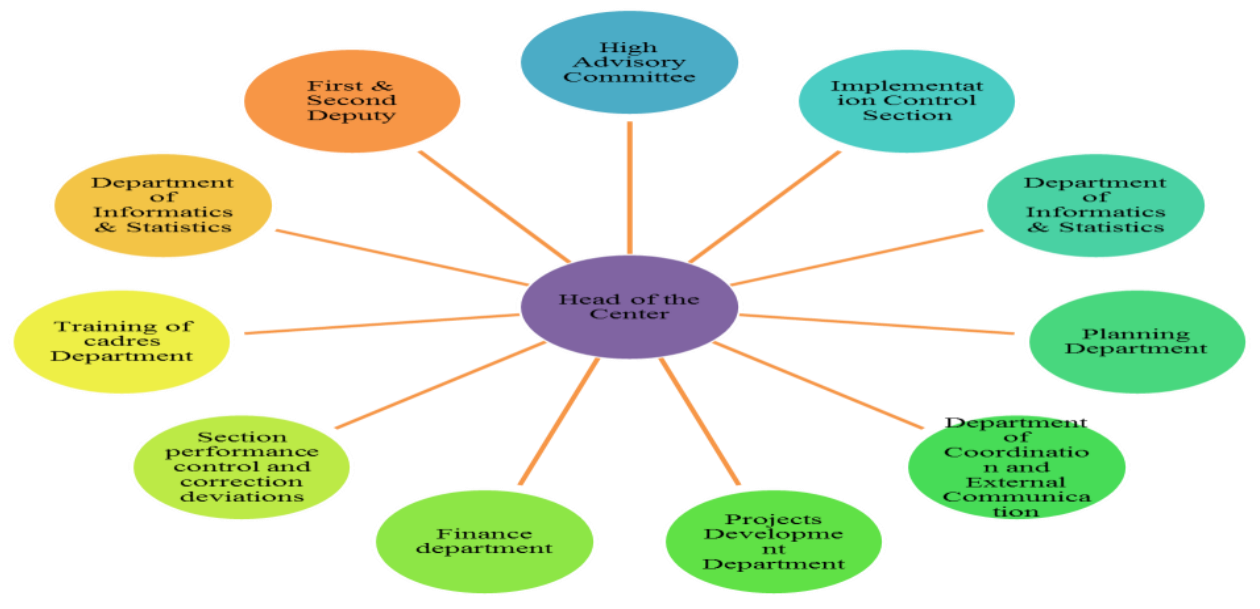

To involve the impoverished population to entrepreneurial activities the authors proposed a "Co-operative Investment Policy"-

Co-operative Investment policy is a micro saving based collective investment scheme, where a 'Co-operative Investment Fund' is created by co-operative micro saving policy and invested in the interest of each investor. It is mainly a profit and loses sharing basis investment activities. It's initiated by little and equal deposit capital of a large number of impoverished investors. At the beginning, monthly basis installment based little but equal deposit capitals from a large number of impoverished investors are entrusted and invested gradually in highly labor productive and profitable sectors as the impoverish 
investors' own financial institutes (SMEs and MIAs) in which they are employed with their shareholder status and get dividend with salaries.

The impoverished investors deposit very little amount of credit $(\$ 5 /$ month) for a certain period of time (2 years) to create an investment fund. After 6 months, when sufficient investment capital is deposited, the fund is directly invested in highly labor productive and profitable sectors including, SMEs (Small and Medium Size Enterprises) and MIAs (Micro Industrial Activities) and employs maximum of its investors (Shareholders) to the financial activities. After a month they start receiving salaries. They receive dividends of the profitable sectors at the same time. They are also allowed to receive collateral free low interest loan from the 'Co-operative Investment Fund' for productive investment, for example, to introduce SMEs or other income generation activities.

As the impoverished people neither have sufficient investment capital nor proper entrepreneurial knowledge and experiences to introduce and operate their own businesses or other income generation activities, 'co-operated investment fund' is created and invested in low risk and labor productive sectors including SMEs and MIAs as their own financial institutes.

\section{Model for Co-operative Investment Policy}

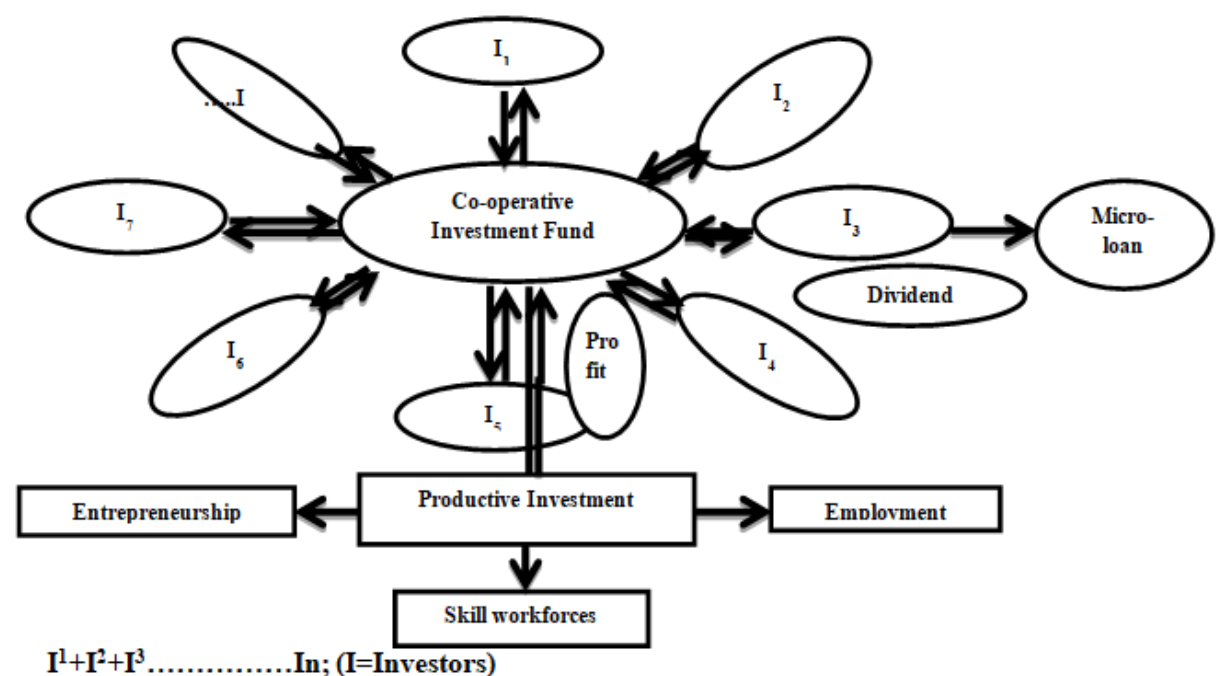

Source: Computation by the Author 2015

Project implementation begins in several stages

I. The first phase is the preparation of investment plans by the Center in coordination with the Government of Bangladesh (ministries and government bodies). In order to start any project, it is necessary to take adequate approvals by government agencies and coordinate with them and accept their advice because these bodies are the only entities to achieve any investment performance, which in turn undertakes to remove any obstacles and provide the infrastructure to start any project

II. The second stage is to go to the poor in Bangladesh to raise awareness and the need for investment by the poor classes of society. This is the necessary stage, which is 
manifested in raising awareness of poor people and saving a little money to start small and medium investments. At this stage, it is possible to use the intellectual society and appropriate media bodies

III. The third stage is to start the process of financial saving within the mechanism of the impact on the minimum acceptable for the pension. The process of saving and financing in the strata of poor societies is complex and difficult because of the lack of quantity available to start any investment project, or perhaps the use of this through borrowing from other sources and ultimately in the case of non-payment leads to the accumulation of the problems of the poor and living in permanent poverty and falling into the trap of slavery.

In order to save money we suggest the following mechanism as shown in the table 4:

\begin{tabular}{|c|c|c|c|c|c|c|}
\hline & $\begin{array}{c}\text { Contrib } \\
\text { ution }\end{array}$ & $\begin{array}{c}\text { Small } \\
\text { credit }\end{array}$ & $\begin{array}{c}\text { Invest } \\
\text { ment }\end{array}$ & $\begin{array}{c}\text { Educa } \\
\text { tion }\end{array}$ & $\begin{array}{c}\text { Saving for 1000 } \\
\text { people for 6 months }\end{array}$ & $\begin{array}{c}\text { Saving for 1000 people for } \\
\text { 6 months for Education }\end{array}$ \\
\hline $1(2 \$)$ & 5 & & 4 & 1 & 24000 & 6000 \\
\hline $1(1.25 \$)$ & 3,125 & 1,875 & 4 & 1 & 24000 & 6000 \\
\hline
\end{tabular}

Source: By author

The savings mechanism is divided into two levels

The first is the per capita income of $\$ 2 /$ daily level; the monthly savings of the level will be $\$ 5$ per person

The second is the per capita income of \$1.25/daily level; the monthly savings of the level will be $\$ \$ 1.75$ per person

On account of $\$ 5 /$ month of 1000 people will be $\$ 5000 /$ month and $\$ 30,000$ in 6 months

Where the savings is divided into two sections of the support of investment education and the section for realizing investment process

\begin{tabular}{|c|c|c|c|c|c|c|}
\hline & $\begin{array}{c}\text { Contribution } \\
\text { total }\end{array}$ & $\begin{array}{c}\text { Credit and } \\
\text { government } \\
\text { Contribution }\end{array}$ & $\begin{array}{c}\text { Investment } \\
\text { total }\end{array}$ & $\begin{array}{c}\text { Education } \\
\text { total }\end{array}$ & $\begin{array}{c}\text { Saving 6 } \\
\text { months total }\end{array}$ & $\begin{array}{c}\text { Saving 6 month for } \\
\text { Education total }\end{array}$ \\
\hline $\begin{array}{c}20 \text { millions } \\
(2 \$)\end{array}$ & 101475000 & - & 81180000 & 20295000 & 487080000 & 121770000 \\
\hline $\begin{array}{c}20 \text { millions } \\
(1.25 \$)\end{array}$ & 61875000 & 39600000 & 81180000 & 20295000 & 487080000 & 121770000 \\
\hline $\begin{array}{c}40 \\
\text { millions }\end{array}$ & 163350000 & 39600000 & 162360000 & 40590000 & 974160000 & 243540000 \\
\hline
\end{tabular}

Source: By author

If it has achieve the savings 40 millions people for 6 months, there will be small and medium projects worth nearly 0.974 billion USD will be savings to support approximately education 0.243 billon. USD

Source: collected by the researcher based on the results of the questionnaire

I. The $4^{\text {th }}$ stage is to invest the entrusted capital. It is the most critical stage. The capital will be invested in low risk labor productive sector to create employments for the depositors (shareholders). The target is to invest in regional raw materials based microindustrial (little handicraft and cottage industry) and commercial activities within the 
regions for the regional markets.

II. The $5^{\text {th }}$ phase is to start implementing projects. After adequate funding is available, any project will be initiated within the plans established by the Center and governmental and non-governmental agencies.

III. Follow-up and removal of obstacles. Start any project accompanied by a lot of internal and external impediments including structural, financial, managerial and functional constraints. Therefore, the Center must intervene in these circumstances to ensure the implementation of projects.

IV. Monitoring and giving advices and consultations. After starting the project performance must be monitored and evaluated. Perform performance control, evaluate results and identify deviations. Thus providing the necessary consultative support.

Performance evaluation is carried out in five phases within the following equation

$\mathrm{Y}=\mathrm{S} 1+\mathrm{S} 2+\mathrm{S} 3+\mathrm{S} 4+\mathrm{S} 5$

$\mathrm{Y}=\frac{S f 1}{S P 1}+\frac{S f 2}{S P 2}+\frac{S f 3}{S P 3}+\frac{S f 4}{S P 4}+\frac{S f 5}{S P 5}$

S1: Evaluation of coordination between Centre and governmental and non-governmental agencies

SF1: The actual degree of coordination

SP1: Expected degree of coordination

S2: Evaluation of the Center's ability to raise the level of poor community education and investment Awareness

SF2: The actual extent of the Center's ability to raise the level of poor community education and investment Awareness

SP2: The expected extent of the Center's ability to raise the level of education of the poor community and investment Awareness

S3: Assess of the center's ability to financial savings

SF3: Real financial savings

SP3: Expected financial savings

S4: Evaluation of project start-up efficiency

SF4: Actual performance

SP4: Expected performance

S5: Evaluating the performance of business projects and achieve the desired goals of projects

SF5: Actual performance

SP5: Expected performance

\begin{tabular}{|c|c|c|c|c|c|}
\hline Indicator & Weak \% & Noticeable \% & Moderate \% & High \% & Very high \% \\
\hline S1 & {$[1.20]$} & {$[21-40]$} & {$[41-60]$} & {$[61-80]$} & {$[81-100]$} \\
\hline S2 & {$[1.20]$} & {$[21-40]$} & {$[41-60]$} & {$[61-80]$} & {$[81-100]$} \\
\hline S3 & {$[1.20]$} & {$[21-40]$} & {$[41-60]$} & {$[61-80]$} & {$[81-100]$} \\
\hline S4 & {$[1.20]$} & {$[21-40]$} & {$[41-60]$} & {$[61-80]$} & {$[81-100]$} \\
\hline S5 & {$[1.20]$} & {$[21-40]$} & {$[41-60]$} & {$[61-80]$} & {$[81-100]$} \\
\hline
\end{tabular}

Source: by author

The center's performance levels were divided into five levels Weak, Noticeable, Moderate, High, Very high. 
Each level gives the ability of the center to achieve the goal and therefore must be the establishment of a consultative body elected by the general poor people to monitor and assess the Center's errors and correct deviations, if any.

\section{Conclusion}

One of the main obstacles for growth of SMEs and alleviation of poverty in Bangladesh is the access complexity of formal financial services accompanied by political depression and economic instability. There is no structure based on a clear strategy for poverty reduction. In spite of the relentless efforts to reduce poverty in Bangladesh, lack of adequate control over performance, spread of bureaucracy, bribery and political instability impede the poverty alleviation goal.

The results have shown that the difference factors investigated in the study namely, weakness of government performance, luck of adequate funding, absence of women in entrepreneurial activities, absence of regulatory centers interested in organizing the saving and investment process etc. hindered growth of SMEs and the economic growth. Therefore, if policy makers can understand the mechanism of investment thinking in the poor society in advance, this would help government to modify their performance or improve their strategies to accelerate the entrepreneurships and decrease the poverty rate in Bangladesh.

\section{References}

Anis Chowdhury, DESA Working Paper no. 89 ST/ ESA/2009/89 Department of Economic \& Social Science, N.Y. 10017, USA

BRAC (2013b) "Microfinance-Dabi", available at: http://www.brac.net/content/microfinancedabi\#.UTYHD6WZbdk, retrived on: 2013-01-15

Chris Hall, "The decline of bank finance for SMEs in APEC" International Journal of Entrepreneurship and Small Business, Jan 2010, Vol. 11, Issue 1, pp. 42-54

Haque, K. M. (2006). "Microfinance in Bangladesh: Major Achievements and New Challenges. Paper proceedings of the SAARCFINANCE Governors' Symposium on Microfinance held in Dhaka, Bangladesh, 15-16 February 2006

James Richardson, "Entrepreneurship and development in Asia International Journal of Entrepreneurship and Innovation Management" Jan 2004, Vol. 4, Issue 5, pp. 469-484

Pang, P. (2008), 'The Role of SMEs in Asian Development-Statement", Asian Development Bank Head of Delegation, Hog Kong and China at the 41st Annual Meeting, Madrid, 5-6 May.

SMEDAN. (2010). Survey Report on Micro, Small and Medium Enterprises (MSMEs) In Nigeria: 2010 National MSME collaborative Survey Retrieved from: http://smedan.gov.ng/images/collaborative $\% 20$ survey $\% 20$ report.smedan-nbs.pdf

The Daily Prothom Alo, 7 Nov. 2017

The Daily Star, 8 March 2015

World Bank 2017 https://data.worldbank.org/indicator/NY.GDP.MKTP.KD.ZG?locations=BD

World Bank. (1994). "Can Intervention Work? The Role of Government in SME Success." Washington, DC: World Bank. 